\title{
ON ONE PROPERTY OF INVERSES OF NONLINEAR OPERATORS ASSOCIATED WITH M-MATRICES
}

\author{
YURIY V. SHLAPAK
}

Abstract. In this paper we show that a certain class of nonlinear operators associated with Mmatrices behaves similarly to M-matrices in the sense that their inverse operators map the cone of positive vectors of $\mathbb{R}^{n}$ to itself. It is also proven that a certain iteration process can be used to find the values of these inverse operators at any point within the cone of positive vectors. Some results of computational experiments based on this iteration process are presented and discussed.

Mathematics subject classification (2010): Primary: 15B48; Secondary: 15A24, 15 A60.

Keywords and phrases: M-Matrix, perturbations, nonlinear operator, inverse operator, cone of positive vectors, monotone fixed point Theorem, iterative process, computational experiment.

\section{REFERENCES}

[1] Y. S. Choi, I. Koltracht, P. J. McKenna, A generalization of the Perron-Frobenius theorem for non-linear perturbations of Stieltjes matrices, Contemporary Mathematics, Volume 281, 2001, pp. 325-330.

[2] Y. S. Choi, I. Koltracht, P. J. McKenna, On eigen-structure of a nonlinear map in $R^{n}$, Linear Algebra and its Applications, 399 (2005), pp. 141-155.

[3] Y. S. Choi, J. Javanainen, I. Koltracht, M. Kostrun, P. J. McKenna, N. Savytska, A fast algorithm for the solution of the time-independent Gross-Pitaevskii equation, Journal of Computational Physics, 190 (2003), pp. 1-21.

[4] R. A. Horn, C. A. Johnson, Topics in Matrix Analysis, Cambridge University Press, 1994.

[5] L. V. Kantorovich, B. Z. Vulikh, A. G. Pinsker, Functional analysis in Semi-ordered Spaces, (in Russian Language), Moscow, GosIzdat Technico-Teoreticheskoi Literatury, 1950.

[6] D. Gottlieb, S. A. Orszag, Numerical Analysis of Spectral Methods: Theory and Applications, (CBMS-NSF Regional Conference Series in Applied Mathematics). Society for Industrial Mathematics, 1987. 